\title{
Activity of EGFR, mTOR and PI3K inhibitors in an isogenic breast cell line model
}

\author{
Sharon Glaysher ${ }^{1}$, Louise M Bolton ${ }^{1}$, Penny Johnson ${ }^{1}$, Christopher Torrance ${ }^{2}$ and lan A Cree C.4* $^{3}$
}

\begin{abstract}
Background: The epidermal growth factor receptor family is expressed in breast cancer, and agents targeting this pathway have single agent effects (e.g. traztuzumab). Development of resistance may be due to the presence of alternative pathways, particularly activation of the PI3K/Akt/MTOR pathway. We have therefore examined the effect of inhibitors of this pathway (ZSTK474 and sirolimus) in combination with the epidermal growth factor (EGFR) inhibitors erlotinib and gefitinib in breast MCF10a isogenic cell lines with EGFR, BRAF, AKT, and PI3K mutations.

Results: PI3K mutation conferred increased activity of EGFR inhibitors against MCF10a cells in comparison with the parental cell line and other mutations studied. Combination of EGFR inhibitors with either the PI3K inhibitor ZSTK474 or the MTOR inhibitor sirolimus showed increased activity.
\end{abstract}

Conclusions: These results are encouraging for the use of combinations targeting the PI3K and EGFR pathway simultaneously. Keywords: MTOR, Erlotinib, Gefinitib, ZSTK474, Sirolimus, MCF10, Breast cancer

\section{Background}

Molecular alterations such as mutations or amplifications in Human Epidermal Growth Factor Receptors (HER) or downstream second messengers such as BRAF, AKT or PIK3CA can constitutively activate growth pathways in various cancers (Figure 1). Deregulated signalling through RAS-RAF-MAPK and PI3K-PTEN-AKT-mTOR pathways via such genetic alterations can result in unrestricted cellular proliferation and increased cell survival. It is for this reason that the development of drugs that specifically target these pathway components has become so popular.

Tumours exhibiting mutations within RTK pathway constituents (e.g. RAS, RAF, PIK3CA, PTEN, AKT, mTOR) or their upstream receptors have shown altered sensitivity to many different pathway targeted inhibitors including trastuzumab (Herceptin $\left.{ }^{\mathrm{Tu}}\right)$ in breast cancer, gefitinib (Iressa $^{\text {tur }}$ ) in non small cell lung cancer (NSCLC), cetuximab $\left(\right.$ Erbitux $\left.^{\mathrm{Tt}}\right)$ in colorectal cancer (CRC) and vemurafenib (Zelboraf ${ }^{\mathrm{m}}$ ) in skin melanoma when compared to their wild type counterparts. This has led to a stratified

\footnotetext{
* Correspondence: i.a.cree@warwick.ac.uk

${ }^{3}$ Department of Pathology, University Hospitals Coventry and Warwickshire, Coventry, UK

${ }^{4}$ Yvonne Carter Professor of Pathology, Clinical Sciences Building, University Hospitals Coventry and Warwickshire, CV2 2DX Coventry, UK

Full list of author information is available at the end of the article
}

approach to cancer treatment within those cancers where a prognostic benefit has been identified with or without the presence of specific activating mutations.

Inhibition of a solitary signal transduction pathway is often inefficient due to the development of resistance through activation of alternative signalling cascades or receptor switching [1,2]. Data from NSCLC suggests that sensitivity to anti EGFR therapy is due to activating mutations within EGFR, which are not present in breast cancer. However, it has also been suggested that antiEGFR strategies may also fail due to the presence of alternate activated pathways in which alternative activating mutations may be present. In breast cancer, HER2 amplification is used to guide the use of trastuzumab, an antibody to HER2, and lapatinib, a dual EGFR and HER2 small molecule targeted agent. Resistance to trastuzumab and lapatinib has been linked to aberrations of the PI3K pathway [3]. PI3K abnormalities including activating mutation of PIK3CA and loss of PTEN are common in breast cancer [3-6]. Other resistance mechanisms include activation of alternate pathways, particularly those involving IGF and HER3 [7-9].

To better understand how different activating mutations affect the sensitivity of RTK pathway targeted inhibition, we tested a set of human non-tumorigenic immortalized breast epithelial cells (MCF10a, obtained from Horizon 


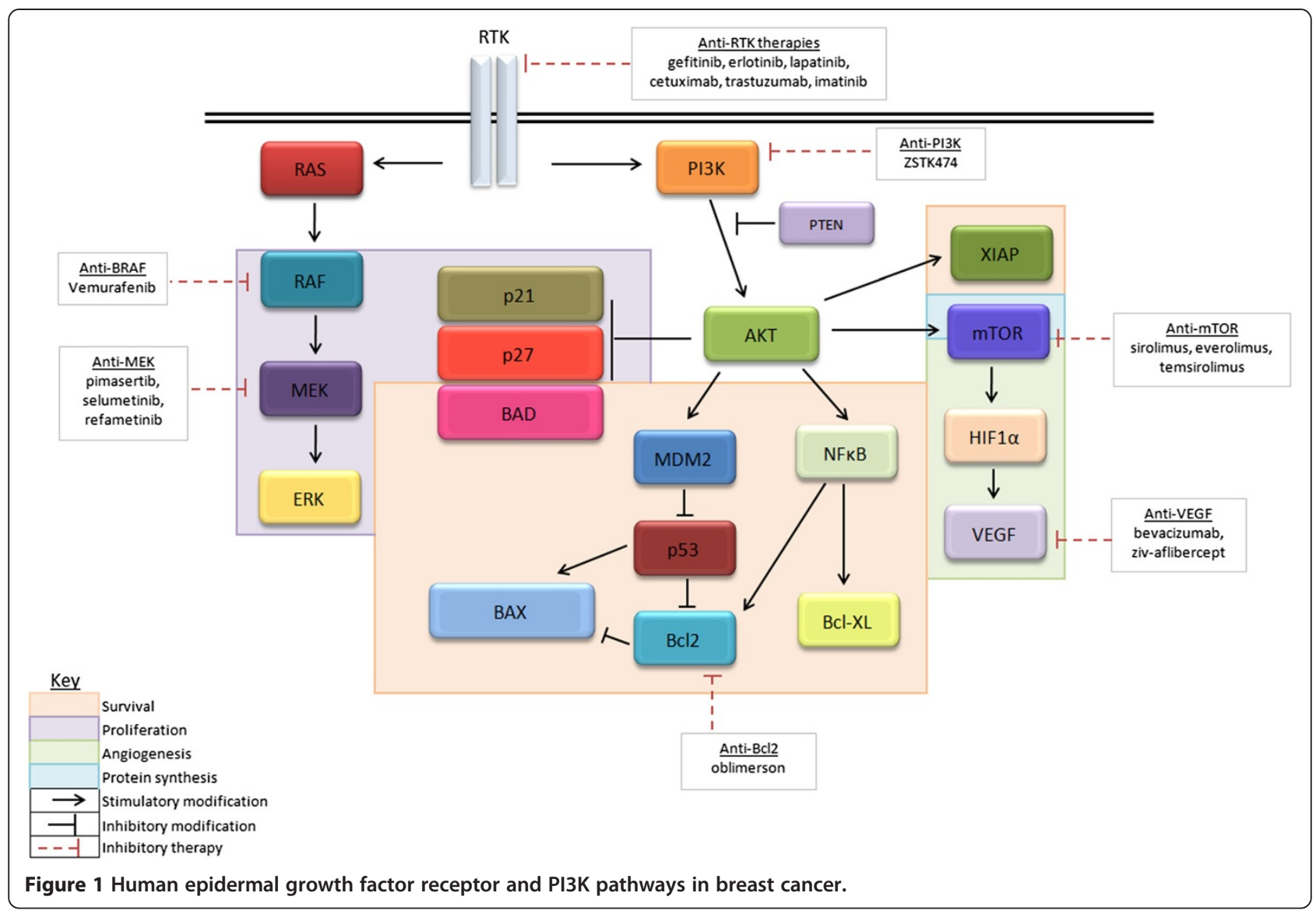

Discovery Ltd) containing known activating mutations in EGFR, BRAF, AKT and PI3K along with the parental line which is wild type for these mutations against growth factor pathway inhibitors.

This isogenic cell line technology used here was initially developed by Di Nicolantonio and colleagues when a panel of isogenic human cell lines were created by employing homologous recombination (by knock-in) to characterize the response of the specific MTOR inhibitor everolimus to those cells containing specific mutations [10]. Using paired cell lines (isogenic and parental); drug sensitivity versus resistance was accurately assessed, with any phenotypic changes being a direct result of the introduced mutations. The DNA-modifications made to these commercially available cell lines are made within the endogenous gene so as to closely recapitulate the genetic events leading to the desired disease of study, or in our case to the effect of drugs targeting altered pathways.

In this study we have used a comparative approach. Mutant and wild type (Wt) MCF10a cells were tested for sensitivity against EGFR/PI3K/mTOR pathway inhibitors gefitinib (Iressa), erlotinib (Tarceva), sirolimus (Rapamycin) and ZSTK474, a pan-PI3K inhibitor as single agents and in combination [11].

\section{Methods}

\section{Cell lines}

Isogenic MCF10a cell lines with mutations in EGFR, BRAF, AKT and PI3K obtained from Horizon Diagnostics (Cambridge) were tested for sensitivity to these targeted inhibitors and compared with their parental MCF10a cell line. The MCF10a parent cell line (also available from ATCC) is immortalised, and was originally grown from adherent epithelia cells from a patient said to have fibrocystic disease. It was chosen by Horizon discovery for their X-man technology as it is easily transfected. It is non-tumorigenic, but does not exhibit senescence. Introduction of new mutations into this line does change its characteristics $[12,13]$ and we believe it to be a good model of the generic effects of PI3K and EGFR inhibition in breast epithelium. Cell lines were grown in accordance to manufacturers' guidelines. All were grown in DMEM:F12 medium with $5 \%$ horse serum, antibiotics (100 units $/ \mathrm{ml}$ penicillin and $0.1 \mathrm{mg} / \mathrm{ml}$ streptomycin), $2 \mathrm{mM} \mathrm{L}$-glutamine, $0.01 \mathrm{mg} / \mathrm{ml}$ insulin, $500 \mathrm{ng} / \mathrm{ml}$ hydrocortisone, $100 \mathrm{ng} / \mathrm{ml}$ cholera toxin, and $20 \mathrm{ng} / \mathrm{ml}$ EGF. Cell lines were grown adherent to plastic in $75 \mathrm{~cm}^{2}$ tissue culture flasks (Fisher Scientific UK; TKV-123-031 L and passaged at regular intervals when they reached 90\% confluence. Cells for 
chemosensitivity assay were harvested by trypsinisation and washed twice in serum-free complete assay medium (CAM) before plating for chemosensitivity assays.

\section{ATP-TCA}

The ATP-Based tumour chemosensitivity assay (ATP-TCA) was performed as previously described $[14,15]$.

(a) Preparation of chemotherapeutic agents Gefitinib, erlotinib, ZSTK474 and sirolimus were purchased from LC Laboratories (Massachusetts, US). All drugs were diluted in CAM (Innovative Diagnostik-systeme) to concentrations thought to be clinically achievable (gefitinib 0.06-2 $\mu \mathrm{M}$, erlotinib 0.2-6.5 $\mu \mathrm{M}$, ZSTK474 0.07-2.2 $\mu \mathrm{M}$, sirolimus 0.06-2 $\mu \mathrm{M})$. Combinations were tested by simultaneous addition. All of the chemotherapeutic drugs or combinations were tested in triplicate at 6 dilutions in 96-well round-bottomed polypropylene microplate (Corning Life Sciences, UK; 3790), allowing four drugs or drug combinations were tested. Two controls were included in one row of each plate: a no drug control consisting of media only (MO) and a maximum inhibitor (MI) control which kills all cells present giving a zero ATP count.

(b) ATP extraction and measurement ATP was extracted from cells by the addition of $50 \mu \mathrm{l}$ of ATP extraction reagent (DCS) to each well of the 96-well plate. Plates were incubated at room temperature for a minimum of 20 minutes and a maximum of one hour before the ATP was read. The ATP in the wells was measured using a luciferin-luciferase counting reagent as previously described [14,15]. Light output was measured using a Berthold Diagnostic Systems MPL1 luminometer (Berthold Diagnostic Systems, Pforzheim, Germany). All luminescence measurements were performed using the manufacturer's instructions and an ATP standard curve run before each read using Adenosine 5'-triphosphate standard disodium salt hydrate (Sigma).

(c) Viability analysis

The data produced from each ATP-TCA plate was entered into an Excel (Microsoft ${ }^{\circledR}$ ) spreadsheet that calculated the percentage tumour growth inhibition at each concentration, the IC50, and IC90 (concentration of drug required to cause 50\% and $90 \%$ inhibition) for each drug as described in $[14,15]$. The percentage tumour growth inhibition at each drug concentration was used to plot curves for each drug or combination. As the variation between the wells that were averaged to calculate the percentage tumour inhibition is small (typical coefficient of variance of less than 10\%), error bars have not been included on most graphs as they are usually smaller than the markers on the graphs. The percentage tumour growth inhibition was calculated as follows:

$$
\begin{aligned}
\% \text { Inhibition }=1.0- & (\text { Test }-\mathrm{MI}) \times 100 \\
(\mathrm{MO}-\mathrm{MI}) &
\end{aligned}
$$

Test $=$ mean counts for test drug wells $\mathrm{MI}=$ mean counts for maximum inhibitor wells $\mathrm{MO}=$ mean counts for medium only wells To allow comparison between different cell lines, a sensitivity index (Index SUM $_{\text {}}$ ) was used to calculate sensitivity based on percentage inhibition for each drug or combination, where IndexSUM = Sum (Inhibition200...6.25\%).

The effects of drug combinations compared with their single agent counterparts were analysed using combination indices. Combination indices (CI) calculated by the Chou and Talalay [16] methods were determined at 50\% and 90\% cell death. These were defined as follows:

$$
\begin{aligned}
& \mathrm{CIA}+\mathrm{B}=[(\mathrm{DA} / \mathrm{A}+\mathrm{B}) / \mathrm{DA}]+[(\mathrm{DB} / \mathrm{A}+\mathrm{B}) / \mathrm{DB}]+ \\
& {[\alpha(\mathrm{DA} / \mathrm{A}+\mathrm{B} \times \mathrm{DB} / \mathrm{A}+\mathrm{B}) / \mathrm{DADB}]}
\end{aligned}
$$

Where CIA $+\mathrm{B}=\mathrm{CI}$ for a fixed effect $(\mathrm{F}=50 \%$ or $90 \%)$ for the combination of cytotoxic $A$ and cytotoxic B; DA/A $+\mathrm{B}=$ concentration of cytotoxic $A$ in the combination $A+B$ giving an effect $F$; $\mathrm{DB} / \mathrm{A}+\mathrm{B}=$ concentration of cytotoxic $\mathrm{B}$ in the combination $\mathrm{A}+\mathrm{B}$ giving an effect $\mathrm{F} ; \mathrm{DA}=$ concentration of cytotoxic A alone giving an effect $\mathrm{F} ; \mathrm{DB}=$ concentration of cytotoxic $\mathrm{B}$ alone giving an effect F. $\alpha=$ parameter with value 0 when $A$ and $B$ are mutually exclusive and 1 when $A$ and $B$ are mutually non-exclusive. The combination index CI calculates synergism $<0.8$; additivity $>0.8$ and $<1.2$; antagonism $>1.2$ [17].

\section{Mutation analysis}

For DNA extraction, the Ambion ${ }^{\oplus}$ RecoverALL $^{\mathrm{TM}}$ Nucleic acid Isolation kit using their total nucleic acid isolation protocol was used with RNase, according to the manufacturer's instructions. Samples were quantified and purity checked using $1.5 \mu \mathrm{l}$ of each undiluted sample with the NanoDrop spectrophotometer.

Rapid mutation screening for common mutations in EGFR, PI3K and BRAF was performed using Therascreen (Qiagen) kits, according to the manufacturer's instructions. PCR was performed in an AB 7500 Fast Dx PCR machine and results downloaded to an Excel spreadsheet for analysis. 


\section{Results}

The ATP-TCA was used to determine the effect of EGFR inhibitors (gefitinib and erlotinib) alone and in combination with inhibitors of the Akt/PI3K/mTOR pathway.

\section{Effect of single agents on isogenic MCF10a cell lines}

(a) EGFR inhibitors

The parental MCF10a cell line showed greater resistance to gefitinib than those with mutations in EGFR, KRAS, PI3K, BRAF and AKT (Figure 2). Greatest sensitivity was seen within the PI3K mutated cells where Index $x_{\text {SUM }}$ values decreased from a relatively resistant index of 423 to 120 and 64 for the H1407R and E545K mutations of PI3KCA respectively. MCF10a cells were more sensitive to erlotinib $\left(\right.$ Index $\left._{\text {SUM }}=188\right)$ than gefitinib $\left(\right.$ Index $\left._{\text {SUM }}=423\right)$. Changes in sensitivity caused by the mutations were less pronounced in response to erlotinib exposure. The PIK3CA mutation E545K still became the most sensitive phenotype, but the effect of an AKT mutation produced a slightly more resistant phenotype (Index SUM $=227)$ when compared with the parental line $\left(\right.$ Index $\left._{S U M}=188\right)$. However, both showed sufficient cellular inhibition to be classed as active agents in this setting with an index $\mathrm{SUM}_{\mathrm{SM}}<300$ representing 50\% inhibition across the range of concentrations tested [18]. (b) PI3K inhibitor

All mutated MCF10a cell lines showed sensitivity to the PI3K inhibitor ZSTK474 (Index SUM $\left._{3}<300\right)$ with EGFR and AKT mutations having no effect on the activity of this agent. Results with these mutations were similar to the parental line. PI3K mutations conferred greater sensitivity to ZSTK474 compared with the parental line, while cells containing the BRAF mutation V600E showed a more resistant phenotype.

\section{(c) mTOR inhibitor}

Sirolimus was the least active of the four inhibitors tested (Figure 2). Only MCF10a cells harbouring EGFR and PIKCA (E545K) mutations showed sensitivity with Index SUM $_{\text {OM }} 272$ and 254 respectively which was an increase compared with the parental line Index ${ }_{\mathrm{SUM}}$ of 333. BRAF mutation containing cells (V600E) again showed the most resistant phenotype with an Index SUM $_{\text {M }}$ of 53.

\section{Effect of combinations on isogenic MCF10a cell lines} Combination of the EGFR inhibitors with either ZSTK474 or sirolimus resulted in greatly increased cellular inhibition (Figure 2), with sensitivity Index $x_{S U M}$ values in all MCF10a cell lines below 200 and corresponding CI indices (Table 1). The effects of mutations on sensitivity were observable with cells containing BRAF mutations, though these showed less sensitivity to combinations when

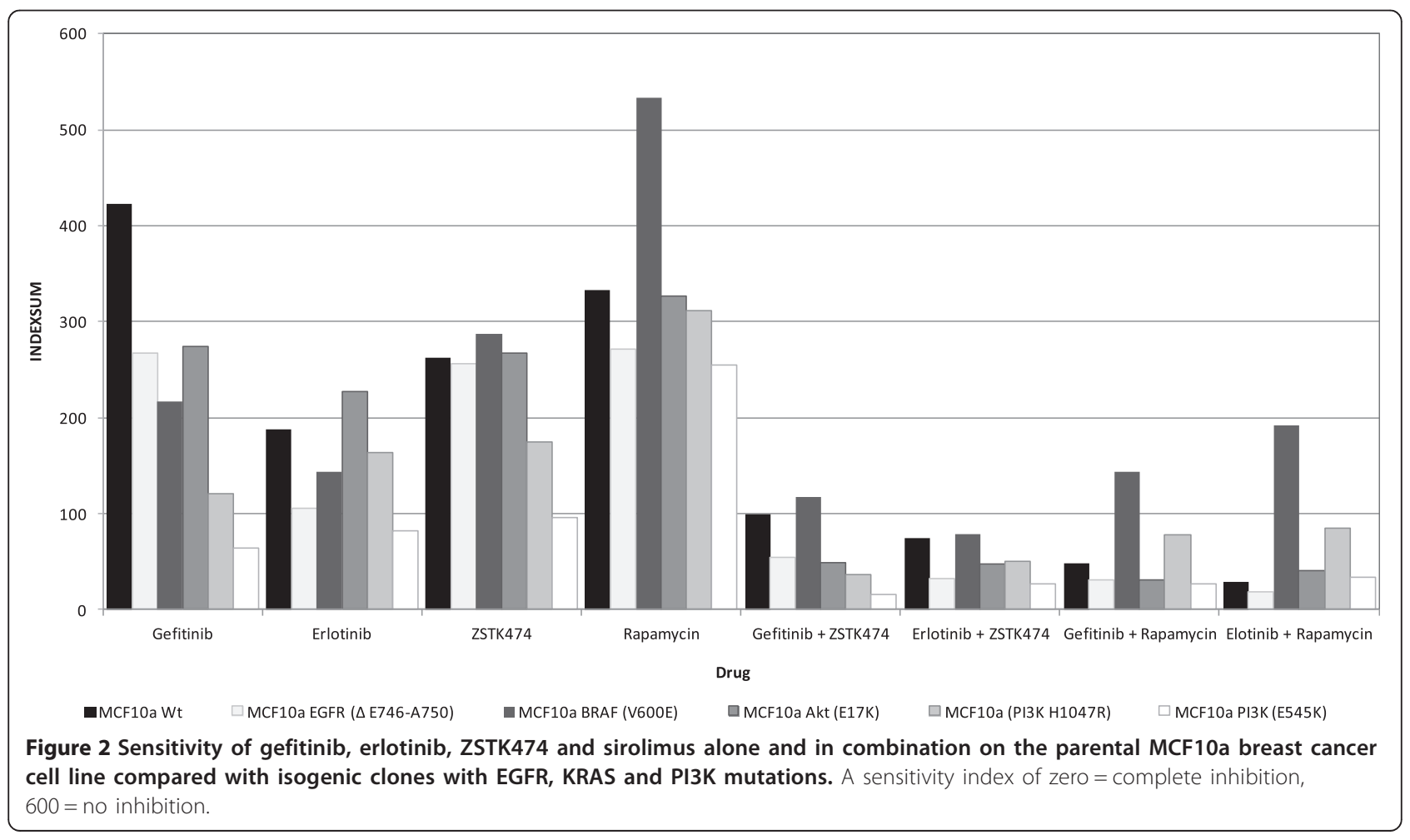


Table 1 Chou and Talalay combination indices for each cell line examined

\begin{tabular}{|c|c|c|c|c|c|c|c|c|}
\hline \multirow[b]{2}{*}{ Cell Line } & $\begin{array}{c}\text { Gefitinib + } \\
\text { ZSTK4744 }\end{array}$ & $\begin{array}{c}\text { Erlotinib + } \\
\text { ZSTK474 }\end{array}$ & $\begin{array}{l}\text { Gefitinib + } \\
\text { Rapamycin }\end{array}$ & $\begin{array}{l}\text { Erlotinib + } \\
\text { Rapamycin }\end{array}$ & $\begin{array}{c}\text { Gefitinib + } \\
\text { ZSTK474 }\end{array}$ & $\begin{array}{c}\text { Erlotinib + } \\
\text { ZSTK474 }\end{array}$ & $\begin{array}{l}\text { Gefitinib + } \\
\text { Rapamycin }\end{array}$ & $\begin{array}{l}\text { Erlotinib + } \\
\text { Rapamycin }\end{array}$ \\
\hline & \multicolumn{4}{|c|}{ C150 } & \multicolumn{4}{|c|}{$\mathrm{C} 190$} \\
\hline MCF10a Wt & 0.23 & 0.58 & 0.02 & 0.28 & 0.47 & 0.42 & 0.03 & 0.07 \\
\hline MCF10a PI3K (H1047R) & 1.15 & 0.93 & 1.09 & 0.89 & 0.18 & 0.39 & 0.46 & 0.40 \\
\hline MCF10a PI3K (E545K) & 1.15 & 1.41 & 1.52 & 1.30 & 0.41 & 0.75 & 0.32 & 0.44 \\
\hline MCF10a EGFR ( $\triangle$ E746-A750) & 0.40 & 0.93 & 0.60 & 1.10 & 0.30 & 0.27 & 0.04 & 0.09 \\
\hline MCF10a BRAF (V 600E) & 0.93 & 1.18 & 0.59 & 1.07 & 0.35 & 0.19 & 1.04 & 1.33 \\
\hline MCF10a Akt (E17K) & 0.37 & 0.51 & 0.20 & 0.33 & 0.18 & 0.18 & 0.05 & 0.08 \\
\hline
\end{tabular}

The combination index $\mathrm{Cl}$ calculates synergism $<0.8$; additivity $>0.8$ and $<1.2$; antagonism $>1.2$. Synergism is noted in the wild type cell line, and in the Akt mutated line while there is some indication of antagonism in one PI3K mutated line.

compared with the parental line. MCF10a cells containing the PI3K mutation H1047R showed little sensitivity to single agent sirolimus, and in combination with EGFR inhibitors were still seen to be more resistant than their parental counterpart, and were more resistant than MCF10a cells containing the PIK3CA E545K mutation.

\section{Mutation status of MCF10a cell lines}

MCF10a cell lines included mutations in EGFR (exon 19 deletion E746-A750), BRAF (c.1799 T > A-V600E), PI3K (c.3140A > G-H1047R and c.1633G > A-E545K) and AKT (c.49G > A-E17K). All cell line mutations were confirmed where Therascreen ARMS kits for the relevant mutation were available (Qiagen Ltd, Manchester): confirmation was obtained for all but the AKT mutation, which was not available as a Therascreen kit. The parental MCF10a cell line was also screened against all available mutation tests to confirm mutation exclusion.

\section{Discussion}

Variation in sensitivity was seen with different mutations for all four single agents. Cells with PIK3CA mutations H1047R and E545K showed greatest single agent sensitivity to the PI3K inhibitor. Interestingly, cells with these mutations also showed greater sensitivity to gefitinib and erlotinib than cells with the EGFR mutation (exon 19 deletion), which are associated with sensitivity to EGFR inhibitors in NSCLC. Mutations in PI3K (H1047R) have been shown to enhance HER2-mediated transformation by amplifying the ligand-induced signaling output of the HER family of RTKs [19]. It could be therefore be assumed that because PIK3CA mutations drive HER related receptor addiction in these cells it would make them more susceptible to RTK inhibition (as seen here with gefitinib and erlotinib) (Figure 1).

Cells containing the PIK3CA mutation E545K were found to be more sensitive than those with the PIK3CA mutation H1047R, suggesting that not all activating mutations found within a given gene will result in the same activity to targeted therapy. Equally cells with activating mutations can react differently to inhibitors of the same target. This is seen here with EGFR mutants as cells with EGFR mutation were significantly more susceptible to erlotinib compared with gefitinib. In reality not all activating mutations within a given gene are comparable in their effect, as has been shown in other tumour types. For instance, it has been suggested that not all KRAS mutations in colorectal cancer are equally effective in conferring resistance to anti-EGFR antibodies [10].

Least inhibition from exposure to the mTOR inhibitor sirolimus was seen in the presence of the BRAF mutation V600E. This is unsurprising given that inhibition of mTOR by sirolimus drives signalling through alternative pathways (AKT/PI3K or MEK/ERK) resulting in hyperactivation of the RAS/RAF/MAPK pathway due to the presence of the BRAF mutation [20-22].

The most effective combinations were of EGFR and PI3K inhibitors. In the presence of gefitinib, PI3K signalling can be maintained by an activated IGF1R pathway $[23,24]$. Therefore it could be suggested that for single agent anti-EGFR therapy to remain effective it would require cells to have EGFR dominant HER signalling in the absence of IGFR signalling pathways. In anti-EGFR resistant tumours showing this profile further alternate signalling mechanisms may be employed, including continued signalling via Met by driving HER3 dependent activation of PI3K. Therefore the combinational strategy of EGFR and PI3K takes advantage of any further downstream signalling through PI3K and is found to be effective despite which mutation is present.

\section{Conclusions}

In breast cancer, there has been considerable interest in the combination of PI3K pathway inhibitors with antiHER2 therapy. Data from different cell lines have been used to justify this [25], but this is to our knowledge the first report using a single parental cell line. Clinical trials are now in progress, and early results are 
encouraging for the combination of trastuzumab and mTOR inhibitors [26]. PI3K inhibitors are also entering clinical trials in combination with HER2 inhibitors [27]. The data presented here support these trials, and support the importance of full molecular characterisation of tumours where possible, suggesting that a more effective strategy in the use of pathway-targeted treatment may come from using the agents in combination to secure a strong signalling blockade.

\section{Competing interests}

CT was a Director of Horizon Discovery Ltd when this work was performed, and IC is a Director of CanTech Ltd. Neither author will gain financially from this publication. The other authors declare that they have no competing interests.

\section{Authors' contributions}

CT and IC conceived and designed the study. SG, LM and PJ carried out the cell culture and molecular studies. SG and IC performed the statistical analysis and wrote the initial draft. All authors participated in review of drafts and approved the final manuscript.

\section{Acknowledgements}

We are grateful to Horizon Discovery Ltd for provision of isogenic X-man ${ }^{\text {TM }}$ cell lines and to CanTech Ltd for funding this work.

\section{Author details}

${ }^{1}$ Translational Oncology Research Centre, Queen Alexandra Hospital, PO6 3LY Portsmouth, UK. ${ }^{2}$ Horizon Discovery Ltd, 7100 Cambridge Research Park, Waterbeach, CB25 9TL Cambridge, UK. ${ }^{3}$ Department of Pathology, University Hospitals Coventry and Warwickshire, Coventry, UK. ${ }^{4}$ Yvonne Carter Professor of Pathology, Clinical Sciences Building, University Hospitals Coventry and Warwickshire, CV2 2DX Coventry, UK.

Received: 8 July 2013 Accepted: 17 June 2014

Published: 25 June 2014

\section{References}

1. Yang L, Li J, Ran L, Pan F, Zhao X, Ding Z, Chen Y, Peng Q, Liang H: Phosphorylated insulin-like growth factor 1 receptor is implicated in resistance to the cytostatic effect of gefitinib in colorectal cancer cells. J Gastrointest Surg 2011, 15(6):942-957.

2. Jain A, Penuel E, Mink S, Schmidt J, Hodge A, Favero K, Tindell C, Agus DB: HER kinase axis receptor dimer partner switching occurs in response to EGFR tyrosine kinase inhibition despite failure to block cellular proliferation. Cancer Res 2010, 70(5):1989-1999.

3. Serra V, Scaltriti M, Prudkin L, Eichhorn PJ, Ibrahim YH, Chandarlapaty S, Markman B, Rodriguez O, Guzman M, Rodriguez S, Gili M, Russillo M, Parra $J \mathrm{~L}$, Singh S, Arribas J, Rosen N, Baselga J: PI3K inhibition results in enhanced HER signaling and acquired ERK dependency in HER2overexpressing breast cancer. Oncogene 2011, 30(22):2547-2557.

4. Berns K, Horlings HM, Hennessy BT, Madiredjo M, Hijmans EM, Beelen K, Linn SC, Gonzalez-Angulo AM, Stemke-Hale K, Hauptmann M, Beijersbergen RL, Mills GB, van de Vijver MJ, Bernards R: A functional genetic approach identifies the PI3K pathway as a major determinant of trastuzumab resistance in breast cancer. Cancer Cell 2007, 12(4):395-402.

5. Serra V, Markman B, Scaltriti M, Eichhorn PJ, Valero V, Guzman M, Botero ML, Llonch E, Atzori F, Di Cosimo S, Maira M, Garcia-Echeverria C, Parra JL, Arribas J, Baselga J: NVP-BEZ235, a dual PI3K/mTOR inhibitor, prevents PI3K signaling and inhibits the growth of cancer cells with activating PI3K mutations. Cancer Res 2008, 68(19):8022-8030.

6. Razis E, Bobos M, Kotoula V, Eleftheraki AG, Kalofonos HP, Pavlakis K, Papakostas P, Aravantinos G, Rigakos G, Efstratiou I, Petraki K, Bafaloukos D, Kostopoulos I, Pectasides D, Kalogeras KT, Skarlos D, Fountzilas G: Evaluation of the association of PIK3CA mutations and PTEN loss with efficacy of trastuzumab therapy in metastatic breast cancer. Breast Cancer Res Treat 2011, 128(2):447-456.
7. Wong AL, Lee SC: Mechanisms of resistance to trastuzumab and novel therapeutic strategies in HER2-positive breast cancer. Int I Breast Cancer 2012, 2012:415170.

8. Sergina NV, Rausch M, Wang D, Blair J, Hann B, Shokat KM, Moasser MM: Escape from HER-family tyrosine kinase inhibitor therapy by the kinase-inactive HER3. Nature 2007, 445(7126):437-441.

9. Lu Y, Zi X, Zhao Y, Mascarenhas D, Pollak M: Insulin-like growth factor-I receptor signaling and resistance to trastuzumab (Herceptin). J Natl Cancer Inst 2001, 93(24):1852-1857.

10. Di Nicolantonio F, Arena S, Tabernero J, Grosso S, Molinari F, Macarulla T, Russo M, Cancelliere C, Zecchin D, Mazzucchelli L, Sasazuki T, Shirasawa S, Geuna M, Frattini M, Baselga J, Gallicchio M, Biffo S, Bardelli A: Deregulation of the PI3K and KRAS signaling pathways in human cancer cells determines their response to everolimus. J Clin Invest 2010, 120(8):2858-2866.

11. Rewcastle GW, Gamage SA, Flanagan JU, Frederick R, Denny WA, Baguley $B C$, Kestell P, Singh R, Kendall JD, Marshall ES, Lill CL, Lee WJ, Kolekar S, Buchanan CM, Jamieson SM, Shepherd PR: Synthesis and biological evaluation of novel analogues of the pan class I Phosphatidylinositol 3-Kinase (PI3K) Inhibitor 2-(Difluoromethyl)-1-[4,6-di(4-morpholinyl)1,3,5-triazin-2-yl]-1H-benzimi dazole (ZSTK474). J Med Chem 2011, 54(20):7105-7126.

12. Pilat MJ, Christman JK, Brooks SC: Characterization of the estrogen receptor transfected MCF10A breast cell line 139B6. Breast Cancer Res Treat 1996, 37(3):253-266.

13. Kadota M, Yang HH, Gomez B, Sato M, Clifford RJ, Meerzaman D, Dunn BK, Wakefield LM, Lee MP: Delineating genetic alterations for tumor progression in the MCF10A series of breast cancer cell lines. PLoS One 2010, 5(2):e9201.

14. Andreotti PE, Cree IA, Kurbacher CM, Hartmann DM, Linder D, Harel G, Gleiberman I, Caruso PA, Ricks SH, Untch M, Sartori C, Bruckner HW: Chemosensitivity testing of human tumors using a microplate adenosine triphosphate luminescence assay: clinical correlation for cisplatin resistance of ovarian carcinoma. Cancer Res 1995, 55(22):5276-5282.

15. Glaysher S, Cree IA: Cell sensitivity assays: the ATP-based tumor chemosensitivity assay. Methods Mol Biol 2011, 731:247-257.

16. Chou TC, Talalay P: Quantitative analysis of dose-effect relationships: the combined effects of multiple drugs or enzyme inhibitors. Adv Enzym Regul 1984, 22:27-55.

17. Greco WR, Bravo G, Parsons JC: The search for synergy: a critical review from a response surface perspective. Pharmacol Rev 1995, 47(2):331-385.

18. Knight LA, Di Nicolantonio F, Whitehouse P, Mercer S, Sharma S, Glaysher S, Johnson P, Cree IA: The in vitro effect of gefitinib ('Iressa') alone and in combination with cytotoxic chemotherapy on human solid tumours. BMC Cancer 2004, 4:83.

19. Chakrabarty A, Rexer BN, Wang SE, Cook RS, Engelman JA, Arteaga CL: H1047R phosphatidylinositol 3-kinase mutant enhances HER2-mediated transformation by heregulin production and activation of HER3. Oncogene 2010, 29(37):5193-5203.

20. Rodrik-Outmezguine VS, Chandarlapaty S, Pagano NC, Poulikakos PI, Scaltriti M, Moskatel E, Baselga J, Guichard S, Rosen N: mTOR kinase inhibition causes feedback-dependent biphasic regulation of AKT signaling. Cancer Discov 2011, 1(3):248-259.

21. Veilleux A, Houde VP, Bellmann K, Marette A: Chronic inhibition of the mTORC1/S6K1 pathway increases insulin-induced PI3K activity but inhibits Akt2 and glucose transport stimulation in 3 T3-L1 adipocytes. Mol Endocrinol 2010, 24(4):766-778.

22. Grant $\mathrm{S}$ : Cotargeting survival signaling pathways in cancer. $J$ Clin Invest 2008, 118(9):3003-3006.

23. Guix M, Faber AC, Wang SE, Olivares MG, Song Y, Qu S, Rinehart C, Seidel B, Yee $D$, Arteaga $C L$, Engelman JA: Acquired resistance to EGFR tyrosine kinase inhibitors in cancer cells is mediated by loss of IGF-binding proteins. J Clin Invest 2008, 118(7):2609-2619.

24. Jones HE, Gee JM, Hutcheson IR, Knowlden JM, Barrow D, Nicholson Rl: Growth factor receptor interplay and resistance in cancer. Endocr Relat Cancer 2006, 13(Suppl 1):S45-S51.

25. Normanno N, De Luca A, Maiello MR, Campiglio M, Napolitano M, Mancino M, Carotenuto A, Viglietto G, Menard S: The MEK/MAPK pathway is involved in the resistance of breast cancer cells to the EGFR tyrosine kinase inhibitor gefitinib. J Cell Physiol 2006, 207(2):420-427.

26. Morrow PK, Wulf GM, Ensor J, Booser DJ, Moore JA, Flores PR, Xiong Y, Zhang S, Krop IE, Winer EP, Kindelberger DW, Coviello J, Sahin AA, Nunez R, 
Hortobagyi GN, Yu D, Esteva FJ: Phase I/II study of trastuzumab in combination with everolimus (RAD001) in patients with HER2-overexpressing metastatic breast cancer who progressed on trastuzumab-based therapy. J Clin Oncol 2011, 29(23):3126-3132.

27. Nahta R, O'Regan RM: Evolving strategies for overcoming resistance to HER2-directed therapy: targeting the PI3K/Akt/mTOR pathway. Clin Breast Cancer 2010, 10(Suppl 3):S72-S78.

doi:10.1186/1756-0500-7-397

Cite this article as: Glaysher et al: Activity of EGFR, mTOR and PI3K inhibitors in an isogenic breast cell line model. BMC Research Notes 2014 7:397.

\section{Submit your next manuscript to BioMed Central and take full advantage of:}

- Convenient online submission

- Thorough peer review

- No space constraints or color figure charges

- Immediate publication on acceptance

- Inclusion in PubMed, CAS, Scopus and Google Scholar

- Research which is freely available for redistribution 